\title{
Composition of the Separated Green Waste in Rural and Urban Area
}

\author{
Anna Báreková1* , Lucia Tátošová1, Vladimír Kišš², Martina Kováčová2 \\ 1 Department of Landscape Planning and Land Consolidation, Faculty of Horticulture and Landscape \\ Engineering, Slovak University of Agriculture in Nitra, ul. Hospodárska 7, 94976 Nitra, Slovakia \\ 2 Department of Water Resources and Environmental Engineering, Faculty of Horticulture and Landscape \\ Engineering, Slovak University of Agriculture in Nitra, ul. Hospodárska 7, 94976 Nitra, Slovakia \\ * Corresponding author's e-mail: anna.barekova@gmail.com
}

\begin{abstract}
The municipalities in Slovakia have a duty to separate biodegradable municipal waste (BDMW) from family houses. This duty can be achieved by home composting or by collection of green waste in bio-bins, which are regularly emptied by a collection company. The collected waste is recycled in a composting plant. The conducted research was focused on identifying the composition of the collected green waste and comparing the environmental behaviour of residents in villages and towns. The analyses conducted showed that the separated BDMW from the urban population has a higher rate of contamination, but a lower rate of compostable kitchen waste compared to the residents in villages.
\end{abstract}

Keywords: green waste, undesirable impurities content, household waste, municipal composting plant

\section{INTRODUCTION}

Biodegradable municipal waste (BDMW) is a highly heterogeneous mixture of different organic materials, which can be varied e.g. by the sorting criteria specified by the municipality, collection system (including types of collection bins), the efficiency of sorting by citizens, socioeconomic factors, etc. [Castagna et al., 2013; Puig-Ventosa et al., 2013]. In order to meet the EU recycling target, municipalities are obligated to separate and recover BDMW from gardens of family houses in Slovakia. BDMW is then processed in the municipal composting plants, creating compost. The BDMW is collected in brown bio-bins, which are usually emptied in two-week intervals. The source segregation of BDMW is also recommended by Montejo et al. [2015] because of high probability of physical contamination in the municipal solid waste (MSW) derived composts. The composition and purity of the collected BDMW affect the quality of the compost. Composting is a process highly valued in waste management, creating a valuable product with soil amendment potential [Cerda et al., 2018]. It occurs in the biochemical processes involving the decomposition of organic matter. Due to its low cost, this method has attracted a lot of interest in many countries. Through using specialised measuring apparatus, it is possible to maintain the optimal process parameters: temperature, humidity, and oxygen, necessary for the growth of microorganisms. It also requires the selection of the appropriate fractions and pre-selected waste [Kucharczyk et al., 2010].

In determining the composition of the source separated BDMW, the content of undesirable impurities is not the only important parameter, but also the proportion of compostable kitchen waste (i.e. green waste from kitchen), which indicates how much BDMW will be subsequently landfilled. Separate collection of kitchen waste has not been introduced in most municipalities of the Slovak Republic and therefore it ends - as a part of MSW - in landfills. Consistent use of bio-bins for green waste (from the garden and kitchen) in family houses could significantly reduce not only the amount of the landfilled MSW but also the proportion of the landfilled BDMW. 
It is necessary to limit the amount of landfilled BDMW and enhance the use of alternative methods of disposal. Municipalities must meet several obligations in the field of biodegradable waste. This includes weight reduction of BDMW, transference to storage, organization of the selective collection, and also providing construction, maintenance and operation of regional plants for processing waste [Kazimierowicz, 2014].

The quantity of generated MSW is influenced by several factors, mainly socioeconomic ones, which include the habits of inhabitants and the level of residents' income [Malinowski et al., 2009; Przydatek, 2015]. The MSWs from the developed and developing countries are significantly different. For example, the Chinese MSW contains largely kitchen waste with its content being over 50\% [Chen et al., 2010]. However, kitchen waste only accounts for $20 \%$ or less of the USA MSW [Staley and Barlaz, 2009]. According to Stejskal et al. [2017], the average annual kitchen bio-waste production in family houses is $58.5 \mathrm{~kg}$ per capita. It is important to know how this sorted kitchen waste is handled by residents. Part of it may be thrown in bio-bins for garden waste or composted in a yard. Thus, the composition of BDMW in bio-bins is also influenced by the lifestyle of the residents, which is very different in highly populated cities and lower populated villages.

Our research was focused on the evaluation of the composition of the BDMW sourced from family houses in rural and urban areas. The conducted quantitative composition analyses of BDMW have not been performed in Slovakia before.

\section{MATERIAL AND METHODS}

The analyses were carried out on the grounds of two composting plants in the Nitra district in southwest Slovakia. The sample of waste from a rural area originated from the municipal association, which composts its waste in the village of Výčapy-Opatovce. The sample of waste from an urban area was analysed in the composting plant of the Nitra city. These composting plants process green waste (meaning compostable garden and kitchen waste) by simple aerobic fermentation. In each composting plant, 6 analyses were performed in 9 months during 3 seasons (in summer and autumn 2016 and in spring 2017). Each analysed sample weighed around $100 \mathrm{~kg}$. The wet weight fraction of garden waste, compostable kitchen waste and the weight and type of impurities were identified. The samples always came from fresh BDMW brought directly from households (from brown bio-bins) on the same day. One $100 \mathrm{~kg}$ sample consisted of several (8 to 12) random BDMW samples, each being hand-sorted and the individual fractions were then weighed. Subsequently, the measured weights were recorded in a table. The collection of samples was repeated until the total sample weight reached min. $100 \mathrm{~kg}$. The detected impurities were sorted by material and weighed.

\section{The composting plant of the municipal association}

The composting plant in the village of Výčapy-Opatovce has an annual processing capacity of 12000 tons of BDMW and processed BDMW originating specifically from private and public greenery from the territory of 57 member municipalities of the association. These are municipalities with a rural type of housing, where brown bio-bins for green waste with a capacity of 120 litres were distributed to family houses (i.e. approximately 25000 households) in September 2014. The emptying interval is 14 days and the collection is interrupted in the winter months (December, January and February). For this reason, the analyses were not perform in winter. The total amount of BDMW processed in the composting plant increases annually. In 2016, 8335 tons of BDMW were processed and in 2017 it was almost 11000 tons. Almost 81000 inhabitants live in the territory of the association and the fee for waste is $18 \mathrm{EUR} \cdot \mathrm{cap}^{-1} \cdot \mathrm{yr}^{-1}$ (it does not depend on the amount of waste). Fact sheets, which are annually distributed to every household, contain the following municipality instructions: Brown bio-bins can be used to discard garden organic waste, residues of fruits and vegetables, old bread, vegetable remnants of food, shells of nuts and eggs, sediment of coffee, tea bags, sawdust and wood shavings.

\section{The composting plant of the Nitra city}

The composting plant has an annual processing capacity of 16000 tons of BDMW and processed BDMW originating specifically from private and public greenery of the city of Nitra. They deployed brown bio-bins (approximately 8000 
units) for green waste with a capacity of 120 litres in urban areas with family houses in September 2015. The emptying interval is 14 days and the collection is carried out all year round. The total amount of processed BDMW in the composting plant increases, similarly as in Výčapy-Opatovce, every year. In 2016, 5730 tons of BDMW were processed and in 2017 it was almost 15200 tons. As of 1 January 2017, 79472 inhabitants lived in the city of Nitra and the fee for waste was 25 EUR $\cdot \mathrm{cap}^{-1} \cdot \mathrm{yr}^{-1}$ (it does not depend on the amount of waste). The fact sheets, which are annually distributed to every household, contain the following municipality instructions: Brown bio-bins can be used to discard garden organic waste (grass, leaves, flowers, weeds, small branches, tree bark), wood shavings, sawdust and ash, wood chips, waste from fruit and vegetables, overripe fruits and vegetables.

\section{RESULTS AND DISCUSSION}

Tables 1 and 2 summarise the measured weights of the individual fractions that were sorted from the analysed BDMW samples. Table 1 contains the data obtained during 6 analyses at the municipal composting plant in Výčapy-Opatovce and thus represents the composition of the BDMW from the rural area. During the first two analyses in summer 2016, the authors analysed a total amount of $203.01 \mathrm{~kg}$ of BDMW, in autumn 2016 it was $204.95 \mathrm{~kg}$ and in spring 2017 it was $207.95 \mathrm{~kg}$. The total weight of all 6 samples was $615.91 \mathrm{~kg}$, with the proportion of kitchen waste representing $3.81 \%_{\mathrm{wt}}$ and the proportion of impurities only $1.58 \%{ }_{\mathrm{wt}}$.
The measured values from table 1 were converted to mass percentage and are shown graphically in Figure 1. As the graph shows, the share of impurities in the rural area varies from 0.34 to $2.81 \%_{\mathrm{wt}}$ and the share of kitchen waste varies from 0.9 to $7.56 \%{ }_{w t}$.

Table 2 contains the data obtained during 6 analyses at the Nitra composting plant and thus represents the composition of BDMW from the urban area. During the first two analyses in summer 2016, the authors analysed a total amount of $201.765 \mathrm{~kg}$ of BDMW, in autumn 2016 it was $215.32 \mathrm{~kg}$ and in spring 2017 it was $206.705 \mathrm{~kg}$. The total weight of all 6 samples was $623.79 \mathrm{~kg}$, while the proportion of kitchen waste was only $1.14 \%$, but the proportion of impurities was up to $3.14 \%$ wt

The measured values from table 2 were converted to mass percentage and are shown graphically in the Figure 2 . The share of impurities in urban area varies from 0.64 to $6.83 \%$ wt and the share of kitchen waste varies from 0.22 to $2.09 \%{ }_{w t}$.

\section{Comparison of the results in urban and rural area}

In order to observe the effect of the seasons on the composition of BDMW from the urban and rural areas, we have summed values of both analyses for each season. A seasonal comparison of the percentages of impurities (Figure 3) shows the relatively low level of impurities in the BDMW from a rural area. It is in accordance with the research conducted by Stejskal [2010b] who explains that the level of purity of BDMW sorting is much higher in small villages than in cities, what is probably caused by the anonymity accompanying

Table 1. Wet weight of sorted fractions in the analysed samples of BDMW from the rural area

\begin{tabular}{|c|c|c|c|c|c|c|c|}
\hline \multirow{2}{*}{$\begin{array}{l}\text { Season } \\
\text { Analysis order }\end{array}$} & \multicolumn{2}{|c|}{ Summer 2016} & \multicolumn{2}{|c|}{ Autumn 2016} & \multicolumn{2}{|c|}{ Spring 2017} & \multirow{2}{*}{ Total sum } \\
\hline & 1. & 2. & 3. & 4. & 5. & 6. & \\
\hline Kitchen waste $(\mathrm{kg})$ & 1.85 & 0.93 & 7.64 & 2.54 & 6.405 & 4.1 & 23.465 \\
\hline Impurities (kg) & 1.89 & 2.9 & 1.601 & 0.355 & 2.095 & 0.882 & 9.723 \\
\hline Garden waste $(\mathrm{kg})$ & 96.12 & 99.32 & 91.859 & 100.955 & 94.5 & 99.968 & 582.722 \\
\hline Total sample (kg) & 99.86 & 103.15 & 101.1 & 103.85 & 103 & 104.95 & 615.91 \\
\hline
\end{tabular}

Table 2. Wet weight of sorted fractions in the analysed samples of BDMW from the urban area

\begin{tabular}{|l|c|c|c|c|c|c|c|}
\hline \multicolumn{1}{|c|}{ Season } & \multicolumn{2}{c|}{ Summer 2016 } & \multicolumn{2}{c|}{ Autumn 2016 } & \multicolumn{2}{c|}{ Spring 2017 } \\
\hline Analysis order & 1. & 2. & 3. & 4. & 5. & 6. \\
\hline Kitchen waste $(\mathrm{kg})$ & 0.33 & 2.095 & 1.78 & 2.27 & 0.225 & 0.4 & 7.1 \\
\hline Impurities $(\mathrm{kg})$ & 6.86 & 4.68 & 0.685 & 0.785 & 0.99 & 5.59 & 19.59 \\
\hline Garden waste $(\mathrm{kg})$ & 93.3 & 94.5 & 104.2 & 105.6 & 100.7 & 98.8 & 597.1 \\
\hline Total sample $(\mathrm{kg})$ & 100.49 & 101.275 & 106.665 & 108.655 & 101.915 & 104.79 & 623.79 \\
\hline
\end{tabular}




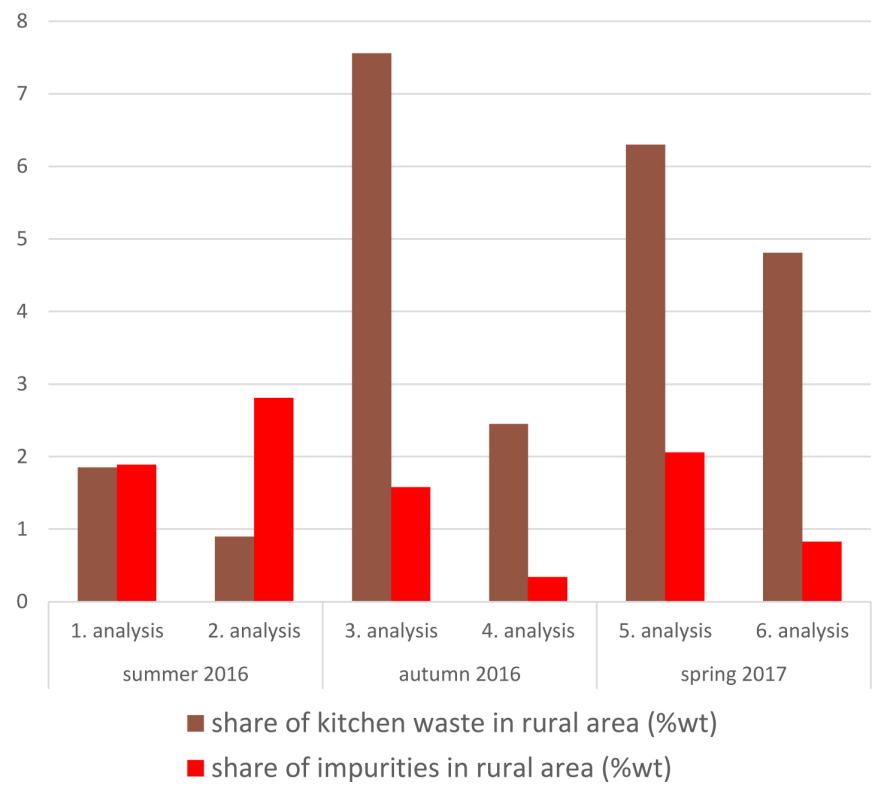

Figure 1. Percentage of sorted fractions in the analysed samples of BDMW from the rural area

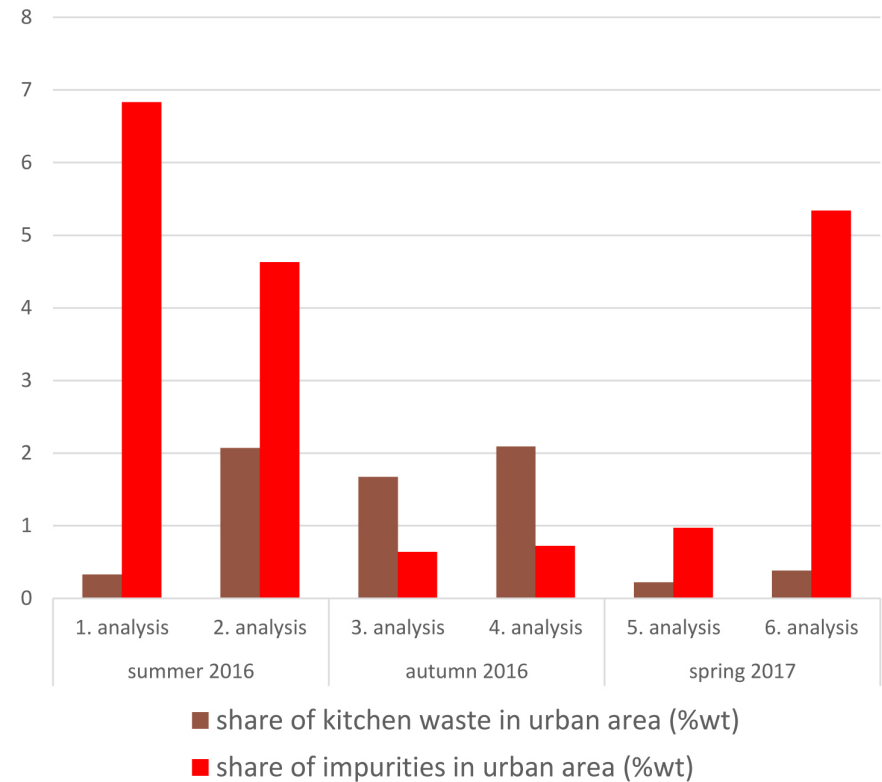

Figure 2. Percentage of sorted fractions in the analyzed samples of BDMW from th eurban area

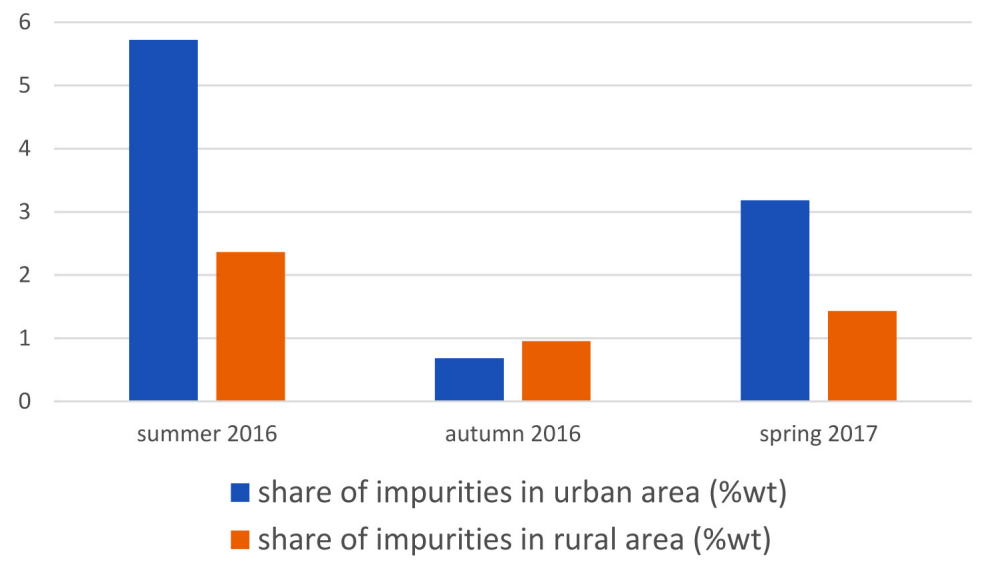

Figure 3. Percentage of impurities in BDMW from the urban and rural areas 


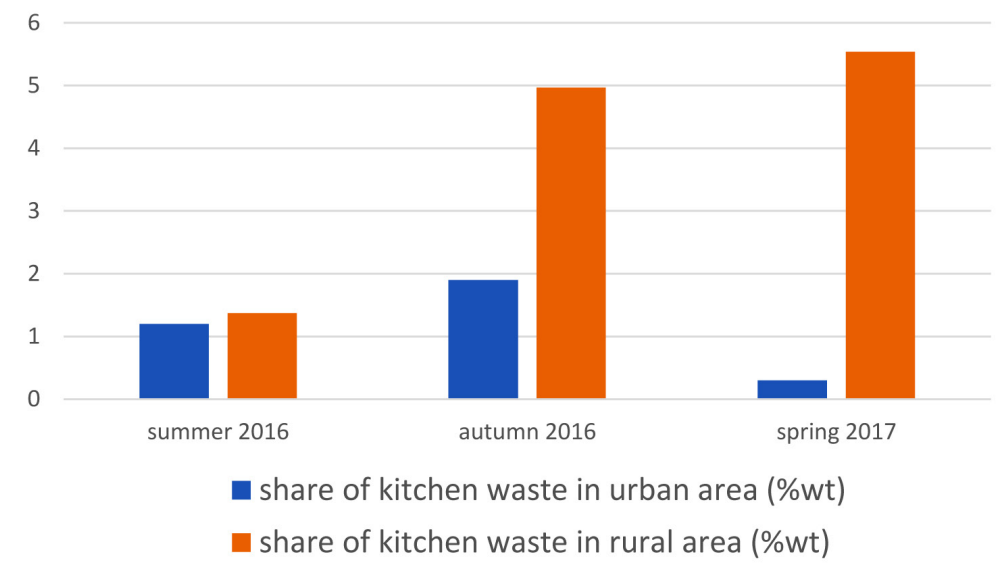

Figure 4. Percentage of kitchen waste in BDMW from urban and rural area

sorting and collection in large cities. In the case of 10 samples (each comprising $200 \mathrm{~kg}$ of BDMW) from small villages, he recorded the rate of impurities exceeding $1 \%{ }_{\mathrm{wt}}$ only once.

According to Stejskal [2010a] the acceptable level of impurities for composting depends on the technological equipment of the composting facility and is usually $1-2 \%$ of impurities in the input raw material. In the association of municipalities, this rate was exceeded only in summer and negligibly $\left(2.36 \%_{\mathrm{wt}}\right)$. An interesting consensus of impurity rates in the urban and rural areas occurred in autumn, when both values were less than $1 \% \%_{w 1}$.

Stejskal [2010a] monitored the quality of sorted BDMW also in the city of Kroměříz (with population of more than 29000 inhabitants) from 28 April 2009 to 4 August 2009. The amount of unacceptable impurities in 10 samples $(200 \mathrm{~kg}$ each) considerably varied from 1 to $9 \%{ }_{\mathrm{wt}}$. He concluded that the amount of unacceptable impurities is too large to allow composting and compost production. BDMW pollution from the city of Nitra (Figure 3 ) exceeded the permissible $2 \%_{\mathrm{wt}}$ rate in summer $\left(5.7 \%_{\mathrm{wt}}\right)$ and also in spring $\left(3.2 \%_{\mathrm{wt}}\right)$.

In the total amount of $19.6 \mathrm{~kg}$ of undesirable impurities in the urban BDMW samples, the following types of waste were most represented: particleboard $\left(29 \%_{\mathrm{wt}}\right)$, animal by-products $\left(18 \%_{\mathrm{wt}}\right)$, metals $\left(18 \%_{\mathrm{wt}}\right)$ and plastics $\left(12 \%_{\mathrm{wt}}\right)$. Regarding the frequency of occurrence of these impurities, in the total number of 58 samples, the authors found plastic up to 22 times, metals 9 times, particleboard 2 times and animal by-products 2 times.

In the total amount of $9.7 \mathrm{~kg}$ of detected undesirable impurities in the BDMW samples from the rural area, plastics $\left(45 \%_{\mathrm{wt}}\right)$, textiles $\left(26 \%_{\mathrm{wt}}\right)$, metals $\left(16 \% \%_{\text {wt }}\right)$ and animal by-products $\left(10 \%{ }_{\text {wt }}\right)$ were the most represented. In total, 57 samplings were performed in this area. The plastics were found in up to 23 , metals in 8 , textiles in 5 and animal byproducts in 3 samples.

A seasonal comparison of the proportion of kitchen waste in BDMW from both areas (Figure 4) indicated that the rural residents throw this waste into bio-bins more often than the city residents, especially in autumn $(5 \%$ wt $)$ and spring $\left(5.54 \%_{\mathrm{wx}}\right)$. This can be caused not only by different lifestyle (higher amount of home produce and home meal preparation), but also by more detailed municipal instructions for using bio-bins.

The share of kitchen waste in BDMW from urban area is less than $2 \%$ which we find very low in proportion. The BDMW composition analyses from family houses in the city of Prague [Hanc et al., 2011] showed that the average proportion of kitchen waste in sorted BDMW was $6.9 \%_{\text {wt }}$. This confirms that a higher level can also be achieved in the case of urban lifestyle.

Detailed data on the compostable kitchen waste representation in the BDMW separated from rural area have not been published yet, and therefore, the comparison of the obtained results with the conclusions from abroad is currently not possible.

\section{CONCLUSIONS}

1. The waste samples in both composting plants were the most polluted during the summer analyses (up to $5.72 \%_{\mathrm{wt}}$ in the urban area and $2.36 \%$ in the rural area).

2 . The results of the research show that the residents of the urban area family houses are less disciplined in adhering to the municipality 
instructions. It could mean that the education of the inhabitants of Nitra city about the disposal procedures should be intensified.

3 . The most frequently occurring contaminants were plastic, metal, textiles and animal by-products.

4. The pollution rate of sorted BDMW was the lowest in both areas in autumn $\left(0.68 \% \%_{\text {wt }}\right.$ in the urban and $0.95 \%$ in the rural area).

5. Our research showed the low proportion of compostable kitchen waste in the investigated samples of BDMW. The kitchen waste suitable for composting represented in the urban area samples only a negligible proportion $\left(1.14 \%_{\text {wt }}\right)$ and the rural population used bio-bins for kitchen waste only in a slightly greater extent $\left(3.81 \%_{\mathrm{wt}}\right)$. This implies that in the landfilled mixed municipal waste, there is still a potentially significant proportion of BDMW, which is suitable for recovery in composting plant or for home composting.

\section{Acknowledgments}

This study was supported by and Slovak Research and Development Agency under the contract No. APVV-15-0562 and Cultural and Educational Grant Agency under the contract No. KEGA-047SPU-4/2017.

\section{REFERENCES}

1. Castagna, A., Casagranda, M., Zeni, A., Girelli, E., Rada, E. C., Ragazzi, M., Apostol, T. 2013. 3R'S from citizens point of view and their proposal from a case-study. UPB Sci. Bull, 75, 253-264.

2. Cerda, A., Artola, A., Font, X., Barrena, R., Gea, T., Sánchez, A. 2018. Composting of food wastes: Status and challenges. Bioresource Technology, 248, Part A, 2018, 57-67.

3. Hanc, A., Novak, P., Dvorak, M., Habart, J., Svehla, P. 2011. Composition and parameters of household bio-waste in four seasons. Waste Manag., 31, 1450-1460.
4. Chen, Y. M., Zhan, L. T., Li, Y. C. 2010. Development of leachate mounds and control of leachaterelated failures at MSW landfills in humid regions. Proceedings of the 6th International Congress on Environmental Geotechnics, New Delhi (2010), 76-98.

5. Kazimierowicz, J. 2014. Organic waste used in agricurtular biogas plants. Journal of Ecological Engineering, 15(2), 2014, 88-92.

6. Kucharczyk K., Stępień W., Gworek B. 2010. Composting of municipal waste as a method of recycling organic matter. Environment and Natural Resources, 42, 240-254.

7. Malinowski Krakowiak-Bal A., Sikora J., Woźniak A. 2009. Ilość generowanych odpadów komunalnych w aspekcie typów gospodarczych gmin województwa małopolskiego. Infrastruktura i Ekologia Terenów Wiejskich, 9, 181-191.

8. Montejo, C., Costa, C., Márquez, M. C. 2015. Influence of input material and operational performance on the physical and chemical properties of MSW compost. J. Environ. Manage., 162, 240-249.

9. Przydatek G., 2015. Analysis of logistic systems of the management of the municipal waste of communes on the area chosen in the context of the sustainable development. Logistyka - Nauka, 3, 4029-4036.

10. Puig-Ventosa, I., Freire-González, J., Jofra-Sora, M. 2013. Determining factors for the presence of impurities in selectively collected biowaste. Waste Manage. Res.: J. Int. Solid Wastes Pub. Clean. Assoc., ISWA, 31, 510-517.

11. Staley, B.F., Barlaz, M.A. 2009. Composition of municipal solid waste in the United States and implications for carbon sequestration and methane yield. Journal of Environmental Engineering, 135(10), 901-909.

12. Stejskal, B. 2010a. Assessment of current quality of biodegradable municipal waste separated by residents of Kroměříž. Acta univ. agric. et silvic. Mendel. Brun., LVIII, No. 4, 209-212.

13. Stejskal, B. 2010b. Bio-waste composting as a part of rural development. Infrastructure and Ecology of Rural Areas, No. 11, 5-13.

14. Stejskal, B., Malsová, A., Báreková, A. 2017. Comparison of family house and apartment households bio-waste production and composition. Waste Forum, No. 4, 237-243. 